\title{
Stability Indicating HPLC Method for the Determination of Diflubenzuron Insecticide
}

\author{
Vinayak Ambike, Anant Argekar* \\ Department of Chemistry, The Institute of Science, Mumbai, India \\ Email address: \\ apargekar@gmail.com (A. Argekar) \\ ${ }^{*}$ Corresponding author
}

\section{To cite this article:}

Vinayak Ambike, Anant Argekar. Stability Indicating HPLC Method for the Determination of Diflubenzuron Insecticide. Science Journal of Energy Engineering. Vol. 5, No. 6, 2017, pp. 152-157. doi: 10.11648/j.sjee.20170506.14

Received: June 30, 2017; Accepted: July 20, 2017; Published: December 1, 2017

\begin{abstract}
A new, fast, accurate, reliable and stability indicating HPLC method for the determination of Diflurobenzuron (DFB), in technical and formulation samples in presence of related and degraded impurities has been developed using intersil 3 stainless steel C. 18 column $(5 \mu \mathrm{m}, 250 \mathrm{~mm}$ length x $4.6 \mathrm{~mm}$ id), acetonitrite: water: 1.4 dioxane (58:39:0.03 v/v) as mobile phase and diphenyl as internal standard. The flow rate of the mobile phase was $2 \mathrm{~cm}^{3} \mathrm{~min}^{-1}$. Detection was carried out at 260 mm using UV detector. The retention times were $1.55 \mathrm{~min}, 1.75 \mathrm{~min}, 6.3 \mathrm{~min}, 7.9 \mathrm{~min}$ and $10.7 \mathrm{~min}$ for 2, 6 diflurobenzoic acid, 2, 6 diflurobuzamide, diflurobenzuron, difur (an impurity) and diphenyl (internal standard) respectively. The linearity range of DFB was 0.5 to $15 \mathrm{mg}$ per $100 \mathrm{~cm}^{3}$. The LOD and LOQ values for DFB were 0.142 to 0.432 respectively. When various technical and formulated smples were analysed by this proposed method the percentage recoveries were found to be $99.20-101.80 \%$ with RSD between $0.01 \%$ to $0.45 \%$.
\end{abstract}

Keywords: Diflubenzuron, Stability Indicating HPLC, Diphenyl Internal Standard

\section{Introduction}

Diflubenzuron (DFB), 1-(4-chlorophenyl)-3-(2, 6 difluorobenzoyl).

Urea(CAS RN-35367-38-5), is a well-known insecticide used for the control of a wide range of insects, pests and larvae of flies, mosquitoes and locusts. It is also ecto parasiticide. DBF is a chitin synthesis inhibitor that act as an anti-moulting agent, leading to death of larvae and pupae [1].

An up to date literature survey indicates that DFB has been analysed by various analytical instrumental techniques like GLC [2, 3, 4] HPLC [5, 6, 7, 8, 9, 10] SFC [10, 12, 13] HPTLC [14] etc. The analytical method for DFB, recommended by CIPAC [15], is HPLC.

In this method C-8 (octyl) column, or alternate, mobile phase containing acetonitrile, water and 1:4 Dioxan, in proportion of 45:40:10 and "Linuron" as internal standard are used. However, due to high concentration of 1:4 Dioxan, the column efficiency is reduced and resolution of DFB and related impurity peaks are affected. Also Linuron, the internal standard, used in this method, is a specific agro product, and may not be available readily in expected pure form.

However, in the present method, C-18 (octadecy 1) column and mobile phase consisting of Acetonitrile: Water: 1:4 Dioxan in the proportion of $58: 39: 03(\mathrm{~V} / \mathrm{V} / \mathrm{V})$ and Biphenyl is used as an internal standard are used. C-18 columns are readily available and are more economic than C-18(Octyl) columns; content of 1:4 Dioxan is very less in the mobile phase and Biphenyl is cheaply available with simple structure and high purity. Moreover, DFB and its related as well as degraded impurities are very well resolved in this method.

\section{Experimental}

\subsection{Instrumentation}

A high-pressure liquid chromatograph, SHIMADZU, equipped with LC-10 AD pump, SPD-10 AV UV/VIS detector with variable wavelength and Controller Bus Module CBM-10 A was used. A photodiode array detector (Shimadzu SPD M 10 A) was also used for confirming the 
peak purities.

\subsection{Chemicals and Solvents}

DFB (technical) procured from M/s. Shimac, China with purity of $95 \%$ was used as a reference standard. Formulation samples of DFB were procured from market.

Acetonitrile and Dioxan used were of HPLC grade supplied by S D Fine Chemicals and SRL respectively, whereas water used was double distilled prepared in the laboratory.

\subsection{Stationary Phase}

Inertsil-3 stainless steel C-18 column $(5 \mu \mathrm{m} ; 250 \mathrm{~mm}$ length X 4.6. mm i. d.) from GE Science Inc., Japan was used as a stationary phase.

\subsection{Mobile Phase}

Acetonitrile: water: 1:4 Dioxan in the volume ratio of 58:39:03.

\subsection{Preparation of Stock Solutions}

Stock solution (A) of DFB was prepared by dissolving 100 $\mathrm{mg}$ of DFB in $50 \mathrm{~cm}^{3}$ of 1:4 Dioxan followed by sonication for about 15 minute and diluted to $100 \mathrm{~cm}^{3}$ with 1:4 Dioxan.

The stock solution (B) of internal standard was prepared by dissolving about $120 \mathrm{mgs}$ of Biphenyl in $50 \mathrm{~cm}^{3}$ of $1: 4$ Dioxan followed by sonication for about $15 \mathrm{~min}$. and diluted to $100 \mathrm{~cm}^{3}$ with 1:4 Dioxan.

\subsection{Preparation of Working Standard Solution}

$10 \mathrm{~cm}^{3}$ of solution (A) was taken in a $100 \mathrm{~cm}^{3}$ volumetric flask and $5 \mathrm{~cm}^{3}$ of solution (B)was added. The solution was diluted to $100 \mathrm{~cm}^{3}$ with the mobile phase.

\subsection{Preparation of Sample Solutions}

Various formulation samples namely technical, wettable powder (WP), wettable dispersible granules (WDG) and suspoconcentrate (SC) were accurately weighed equivalent to $10 \mathrm{mg}$ of DFB, in duplicate, and transferred to $100 \mathrm{~cm}^{3}$ flask containing $50 \mathrm{~cm}^{3}$ of 1:4 Dioxan and sonnicated for 15 minutes and then diluted to $100 \mathrm{~cm}^{3}$ with $1: 4$ Dioxan. $10 \mathrm{~cm}^{3}$ of this solution was mixed with $5 \mathrm{~cm}^{3}$ of internal standard (solution B) and diluted to $100 \mathrm{~cm}^{3}$ with mobile phase. This solution was filtered through Whatman no.1 filter paper to obtain clear solution before injection.

In the case of WDG samples, the material was crushed to fine powder in a mortar before weighing and in case of suspo-concentrate formulation (SC) $20 \mathrm{~cm}^{3}$ of water was added to ensure complete dispersion before dissolving in $50 \mathrm{~cm}^{3}$ of 1:4 Dioxan.

\subsection{Chromatographic Conditions}

Column: Inertsil-3 stainless steel C-18 column, $5 \mu \mathrm{m}$; $250 \mathrm{~mm}$ length X $4.6 \mathrm{~mm}$ i. d. Flow rate: $2 \mathrm{~cm}^{3} \mathrm{~min}^{-1}$

\author{
Detector: UV-260 nm \\ Range: 1.0 AUFS \\ Attenuation: 9 AUFS \\ Injection volume: $20 \mu 1$
}

\subsection{Procedure for Calibration}

Into a series of $100 \mathrm{~cm}^{3}$ flasks, varying amount of stock solution A (1 to $\left.16 \mathrm{~cm}^{3}\right)$ were taken and $5 \mathrm{~cm}^{3}$ of internal standard solution (B) was added. The contents were diluted up to the mark with the mobile phase. $20 \mu \mathrm{l}$ of each solution was injected into the column and peak area ratios were recorded for all the Chromatograms. Calibration curve constructed by plotting peak area ratio (Y-axis) against the amount of DFB in $\mathrm{mg} / \mathrm{cm}^{3}$ (X-axis) and the linear relationship was evaluated by calculation of regression line by the method of least squares.

\subsection{Assay Procedure}

Each of the sample solution, prepared as above in duplicate, was injected in the column and the peak area was recorded as described in calibration procedure. The amount of DFB was computed by internal standard quantification using following equation:

DFB content, percent by mass $=M_{1} X A_{2} X A_{3} X P$

$\mathrm{M}_{2} \mathrm{X} \mathrm{A}_{1} \mathrm{X} \mathrm{A}_{4}$

Where

$\mathrm{M}_{1}=$ mass, in mgs. of DFB ref. standard taken

$\mathrm{M}_{2}=$ mass, in mgs. of DFB sample taken

$\mathrm{A}_{1}=$ Peak area of DFB ref. standard obtained

$\mathrm{A}_{2}=$ Peak area of DFB sample obtained

$\mathrm{A}_{3}=$ Peak area of internal standard obtained in sample

$\mathrm{A}_{4}=$ Peak area of internal standard obtained in ref. Std.

$\mathrm{P}=$ Percentage purity of ref. standard

\section{Results and Discussions}

\subsection{Chromatography}

The mobile phase comprising of Acetonitrile: water: 1:4 Dioxan in the proportion of 58:39:03 was selected because it was ideal to resolve DFB, Difur (an impurity) and Biphenyl (internal standard) with retention times of $6.3 \mathrm{~min}$., $7.90 \mathrm{~min}$. and $10.7 \mathrm{~min}$. respectively (Figure 1). Also the impurities, formed due to degradation, namely 2, 6 difluorobenzamide and 2, 6 Difluoro Benzoic acid are also well resolved from DFB (Figure 2). Solutions of DFB, Difur and Biphenyl in 1:4 Dioxan gave maximum absorption at $259 \mathrm{~nm}, 262 \mathrm{~nm}$ and 248 $\mathrm{nm}$ respectively. $260 \mathrm{~nm}$ was selected for detection, because at this wavelength all the three components gave measurable absorbance (Figure 3). Since 1:4 Dioxan content in the mobile phase was minimum, the column performance was not affected and the results obtained were highly reproducible. The peak purities of DFB Difur and Biphenyl were confirmed using PDA detector. The chromatographic parameters of the system are give in Table-3. 


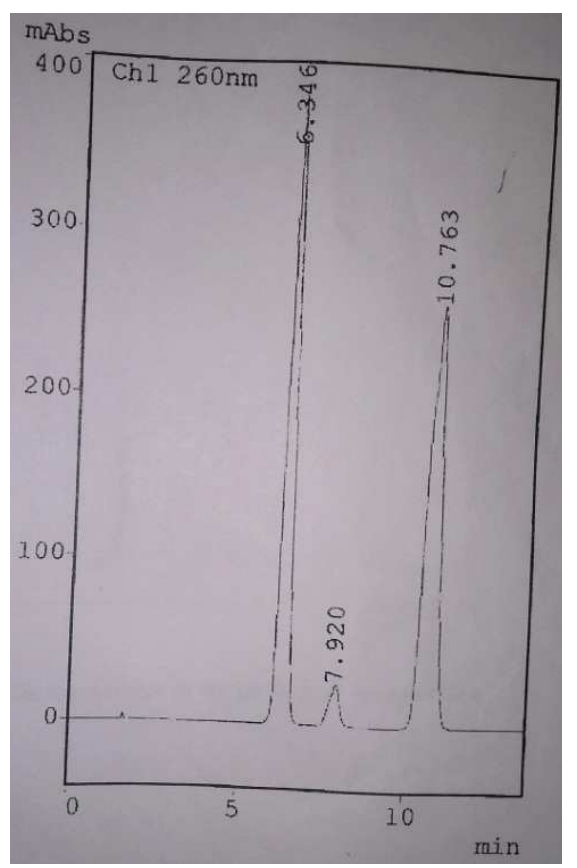

1 DFB 2 Difur 3 Biphenyl

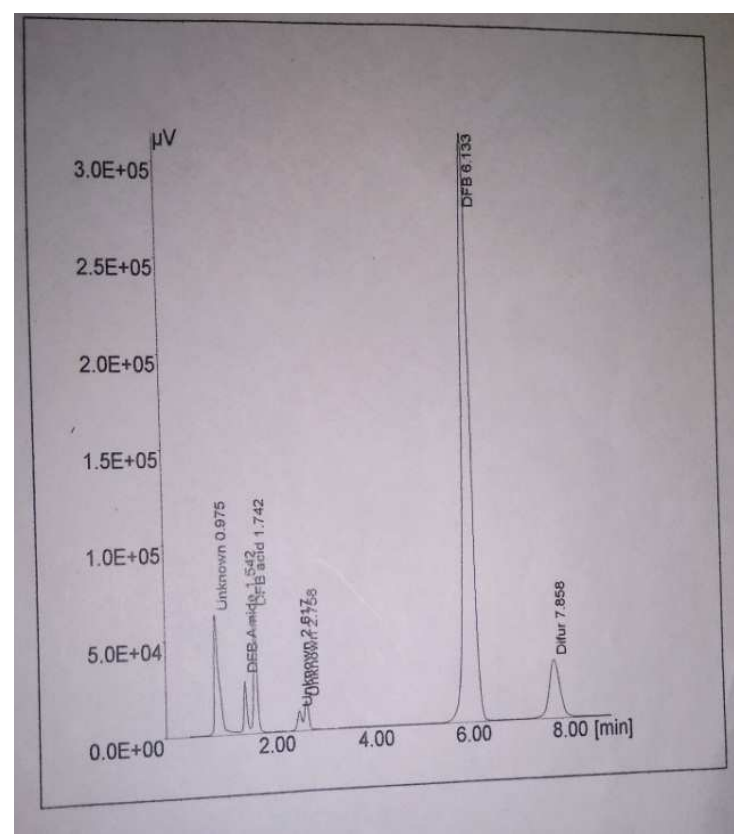

1 Unknown 2 DFB-amide 3 DFB acid 4 Unknown 5 Unknown 6 DFB 7 Difur

Figure 2. Chromatogram of $D F B$ and impurities.

Figure 1. Chromatogram of DFB, Difur and Biphenyl.

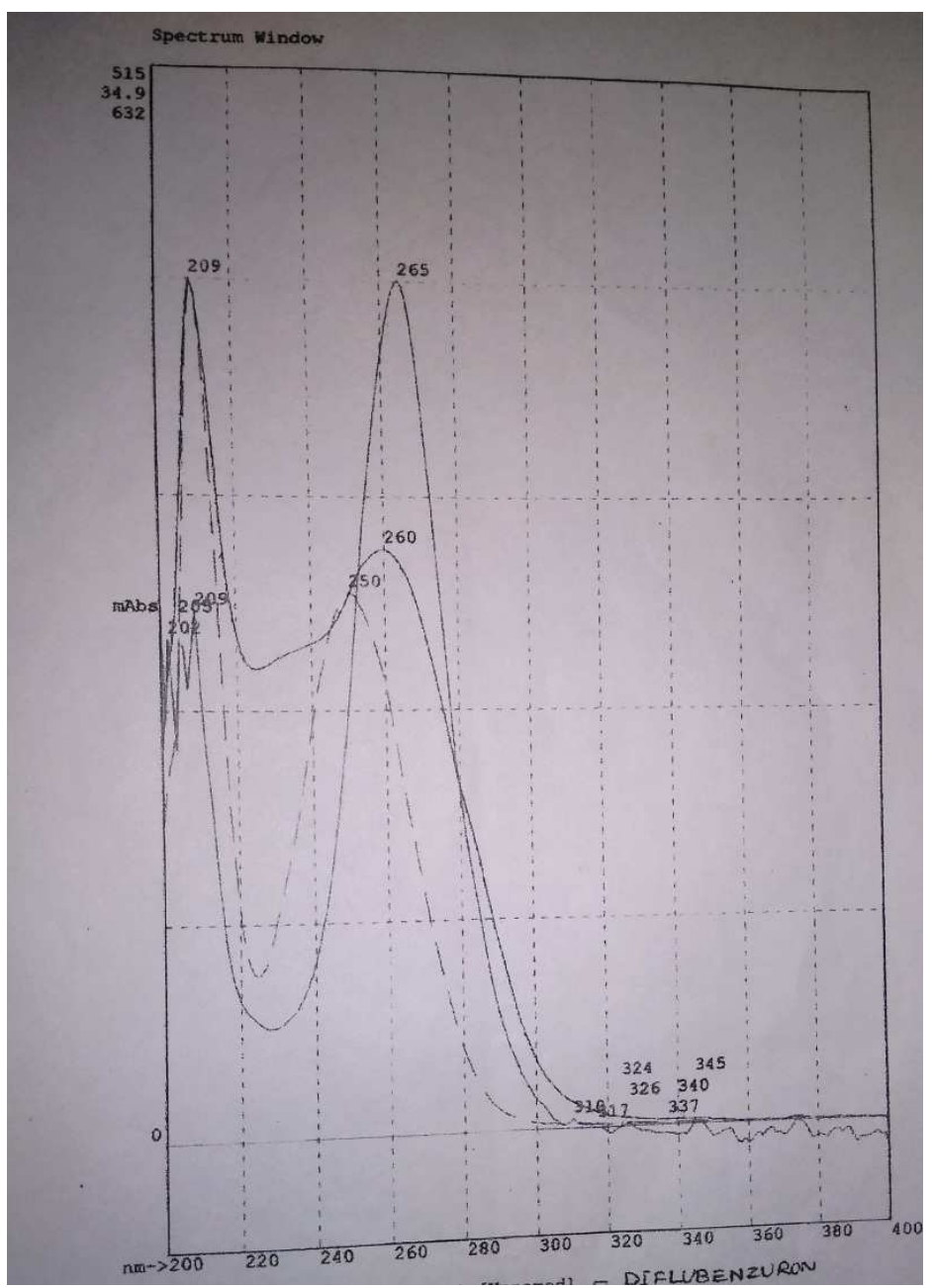

Figure 3. PDA scan of DFB, Difur and Bipheny. 


\subsection{Linearity, Limit of Detection and Limit of Quantification}

The plot of peak area ratios versus the respective concentration of DFB was found to be linear in the range form $0.5 \mathrm{mg}$ to $15 \mathrm{mg} / 100 \mathrm{~cm}^{3}$ (Table-2). The limit of detection (LOD) and limit of quantification (LOQ) were calculated by using the equations,

$\mathrm{LOD}=3.3 \times \sigma / \mathrm{S}$ and $\mathrm{LOQ}=10 \times \sigma / \mathrm{S}$

Where, ' $\sigma$ ' the noise elimination, is the standard deviation of the blank responses (six injections) and ' $\mathrm{S}$ ' is the slope of corresponding calibration curve of DFB. LOD and LCQ values were found to be 0.142 and 0.432 respectively

\subsection{Assay}

Contents of DFB found in the commercial brand of samples by the present method are as shown in the Table-3. The low values of RSD indicate that the method is precise and accurate.

Table 1. Chromatographic Parameters.

\begin{tabular}{lllll}
\hline Parameter & Values (mean) & & \% RSD (N=5) \\
\hline & DFB & BIPHENYL & DFB & BIPHENYL \\
\hline Theoretical plates & 7408 & 9963 & 1.7 & 2.19 \\
Capacity & 659.2 & 1157 & 0.07 & 0.11 \\
Asymmetry & 1.4 & 1.44 & 1.88 & 1.38 \\
Retention time & 6.34 & 10.76 & 0.11 & 1.13 \\
Resolution & -- & 12.04 & - & 1.14 \\
\hline
\end{tabular}

Table 2. Linearity Study.

\begin{tabular}{lll}
\hline Amount of DFB std Taken in mgs & Area ratio $(\mathbf{n}=\mathbf{3})$ & \% RSD \\
\hline 0.5 & 0.047 & 0.45 \\
1.0 & 0.10 & 0.31 \\
2.0 & 0.184 & 0.52 \\
5.0 & 0.496 & 0.12 \\
10.0 & 0.930 & 0.18 \\
15.0 & 1.396 & 0.07 \\
\hline
\end{tabular}

Regression Output:

Slope: 0.09288

R Squared: 0.99995

Std. Err. Of Y Est (): 0.00401

No. of Observations: 6

Degree of Freedom: 4

' $\mathrm{X}$ ' Coefficient: 0.00141

Table 3. Sample Analysis (assay).

\begin{tabular}{|c|c|c|c|c|c|}
\hline Sr. No & Sample & Qty in mgs & Amt of DFB found in mg & Purity\% & \%RSD \\
\hline \multirow[t]{2}{*}{1} & Techn. tel\#1 & 11.74 & 11.23 & 97.5 & 0.24 \\
\hline & & 9.66 & 9.22 & 95.4 & \\
\hline \multirow[t]{2}{*}{2} & Tech \# 2 & 16.84 & 10.35 & 95.5 & 0.27 \\
\hline & & 9.95 & 9.48 & 95.3 & \\
\hline \multirow[t]{2}{*}{3} & $25 \mathrm{WB} \# 1$ & 40.86 & 10.50 & 25.7 & 1.09 \\
\hline & & 42.08 & 10.61 & 25.1 & \\
\hline 4 & & 42.08 & 10.61 & 25.4 & \\
\hline \multirow[t]{2}{*}{5} & 25 WDG\#1 & 40.32 & 9.59 & 23.8 & 1.47 \\
\hline & & 409 & 9.93 & 24.3 & \\
\hline \multirow[t]{2}{*}{6} & 25 WDG\#2 & 42.20 & 10.55 & 24.9 & 0.42 \\
\hline & & 43.72 & 1097 & 25.1 & \\
\hline 7 & $5 \mathrm{SC} \# 6$ & 152.23 & 7.61 & 5.0 & 2.29 \\
\hline \multirow[t]{2}{*}{8} & $25 \mathrm{SC} \# 5$ & 43.46 & 10.95 & 25.2 & 0.28 \\
\hline & & 40.26 & 10.10 & 25.1 & \\
\hline
\end{tabular}

\subsection{Accuracy and Precision}

To study the accuracy and precision of the present method, the recovery experiments were performed by standard addition technique. Four different levels of standards were added to pre-analyzed samples and each level was repeated thrice. The 
percentage recoveries in the samples were in the range of 99.4 to 100.25 for technical, 99.7 to 101.7 for $25 \mathrm{WP}, 99.2$ to 101.5 for 25 WDG and 99.4 to 101.8 respectively (Table-4)The results indicate that there is no interference due to excipients present in the formulations ( $\%$ RSD $\leq 0.4$ max.).

Table 4. Sample Recovery Study.

\begin{tabular}{|c|c|c|c|c|c|}
\hline Blank value in mgs & Amount of std added in mgs & Avg. area ratio $(n=3)$ & $\begin{array}{l}\text { Amount of DFB } \\
\text { recovered in mgs }\end{array}$ & $\begin{array}{l}\text { Recovery } \\
\text { in } \%\end{array}$ & RSD \% \\
\hline DFB Tech. \# (purity = 95.5\%) & Sample weights $=104.8 \mathrm{mgs}$ & & & & \\
\hline 10.35 & NIL & 1.061 & 10.29 & 99.40 & 0.01 \\
\hline 10.35 & 0.5 & 1.123 & 10.88 & 100.25 & 0.10 \\
\hline 10.35 & 1.0 & 1.182 & 11.34 & 99.91 & 0.36 \\
\hline 10.35 & 2.0 & 1.293 & 12.24 & 99.08 & 0.40 \\
\hline 10.35 & 3.0 & 1.430 & 13.66 & 100.12 & 0.20 \\
\hline 10.5 & NIL & 1.156 & 10.47 & 99.7 & 0.14 \\
\hline 10.5 & 0.5 & 1.241 & 11.19 & 101.70 & 0.22 \\
\hline 10.5 & 1.0 & 1.304 & 11.56 & 100.5 & 0.35 \\
\hline 10.5 & 2.0 & 1.46 & 12.62 & 100.96 & 0.12 \\
\hline 10.5 & 3.0 & 1.596 & 13.47 & 99.76 & 0.14 \\
\hline DFB. $(25 \mathrm{WDG}) \# 2(\mathrm{~A} \%=25 \%)$ & Sample weights $=437.2 \mathrm{mgs}$ & & & & \\
\hline 10.97 & NIL & 1.076 & 10.88 & 99.20 & 0.18 \\
\hline 10.97 & 2.0 & 1.382 & 13.17 & 101.54 & 0.16 \\
\hline 10.97 & 3.0 & 1.537 & 14.07 & 100.87 & 0.17 \\
\hline DFB. $(5 \mathrm{SC}) \# 6(\mathrm{~A} \%=4.8 \%)$ & Sample weights $=2015.2 \mathrm{mgs}$ & & & & \\
\hline 9.87 & NIL & 1.056 & 9.91 & 100.4 & 0.14 \\
\hline 9.87 & 0.5 & 1.112 & 10.40 & 99.40 & 0.24 \\
\hline 9.87 & 1.0 & 1.168 & 10.85 & 99.85 & 0.45 \\
\hline 9.87 & 2.0 & 1.289 & 11.96 & 100.78 & 0.28 \\
\hline 9.87 & 3.0 & 1.424 & 13.10 & 101.80 & 0.25 \\
\hline
\end{tabular}

\subsection{Stability Indicating Ability of the Method}

In a series of five volumetric flasks of $100 \mathrm{~cm}^{3}$ capacity, 10 mgs of DFB were taken and $5 \mathrm{ml}$ of $1 \mathrm{~N} \mathrm{NaOH}$ were added to each flask and kept aside for undergoing alkali hydrolysis. After every $24 \mathrm{hrs}$. one of the flasks were treated with $1 \mathrm{~N} \mathrm{HC}$ 1 to neutralize to $\mathrm{pH} 7$ and the solution was diluted up to the mark with mobile phase and $20 \mu \mathrm{l}$ of each were then injected in the HPLC column and the present procedure was followed to analyze DFB. It was observed that the decomposed neutralized solution gave a number of low retention products, the percentage of which significantly increased from 1 to 5 days as shown in Table-5. The impurities decomposition products at retention times $1.55 \mathrm{~min}$. and $1.75 \mathrm{~min}$. were confirmed to be 2, 6 Difluorobenzamide and 2, 6 Difluoro Benzoic acid by spiking the standards of these compounds however, other impurities/products could not be identified due to non-availability of standards.

These results indicate that a present method is a stability indicating method since the method can be not only for assay of DFB but also the impurities like Difur, 2, 6 Difluoro Benzoic acid, 2, 6 Difluorobenzamide without interference.

Table 5. Decomposition Study.

\begin{tabular}{|c|c|c|c|c|c|c|c|}
\hline & Imp.-1 (1 min.) \% & Imp-2 (1.5 min.) \% & Imp-3 (1.8 min.) \% & Imp-4 & Imp-5 & DFB & Difur \\
\hline Day 1 & 14.3 & 0.27 & 3.5 & 1.07 & 1.26 & 71.78 & 7.58 \\
\hline Day 2 & 35.4 & 0.23 & 3.28 & 0.93 & 1.05 & 52.50 & 6.61 \\
\hline Day 3 & 40.2 & 0.21 & 2.93 & 0.88 & 1.00 & 48.91 & 5.54 \\
\hline Day 5 & 49.0 & 0.17 & 2.50 & 0.77 & 0.84 & 41.97 & 4.67 \\
\hline
\end{tabular}

[3] Nigg H N, Cannizzaro R D, Stamper J H, Bull. Environ. Contam. Toxicol., Jun 1986, 36(6), 833-838.

\section{References}

[1] 'Diflubenzuron', Metabolic Pathways of Agrochemicals, PartII (Insecticides and Pesticides), Editor- T. Roberts and D. Hutson, RSC publications 1999, 344.

[2] Mensah J K, Lundanes E, Grebrokk T, Holen B, J. Chromatogr. A, 21 Mar, 1997, 765(s1), 85-90.
[4] Wimmer M J, Smith R R, Jones J P, J. Agric. Food Chem., Feb 1991, 39(2), 280-286.

[5] Rodriguez E, Barrio R J, Goicolea A, Gomez de Balugera Z, Anal. Chim. Acta, 22 Mar 1999384 (1), 63-70.

[6] Rodriguez E, Gomez de Balugera Z, Guicolea M A, Barrio R J, J. Liq. Chromatogr. Relat. Technol., Jul 1998, 21 (12)' 18571870 . 
[7] Gao B F, Jin X H, Fang C G, Fang Q X, Zhang Y Q, Yu W B, Fenxi Huaxue, Jul 1996, 24(7), 865(Chinese).

[8] Bicchi C, Balbo C, Binello A, J. High Resolut. Chromatogr., Feb 1996, 19(2), 105-110.

[9] Terashi A, Eto S, Takano K, Shokunin Eiseigaku Zasshi, Apr 1993, 34(2), 114-119 (Japanease).

[10] Sundaram K M S, Nott R, J. Liq. Chromatogr. 1989, 12(12), 2333-2343.

[11] Bicchi C, Balbo C, D' Amato A, Panero O Chromatographia, Oct 1996, 43 (7-8).
[12] Brede C, Lundanes E. J. Chromatogr. A, 29 Sep 1995, 712(1), 95-101.

[13] Knowles D E, Richter B E, Anderson M R, Later D W. Chim. Oggi., Jan-Feb 1989, 7 (1-2), 11-15.

[14] Sherma J., Rolfe C. J Chromatogr., 23 Jul 1993, 643(1-2), 337-339.

[15] CIPAC Handbook Volume H, 'Analysis of technical and formulated pesticides', Editor-W Dorbat and A Martin, CIPAC Limited, 1998, pp. 141-146. 